\title{
Multivariate analysis of textural properties of butternut squash during thermal treatment
}

\author{
Zofia Hanusz $^{1}$ - Beata Ślaska-Grzywna ${ }^{2}$ - Agata Blicharz-Kania ${ }^{2} \cdot$ Kamila Klimek $^{1}$ - Dariusz Andrejko² \\ Monika Stoma ${ }^{3}$
}

Received: 3 May 2018 / Accepted: 23 August 2018 / Published online: 3 September 2018

(c) The Author(s) 2018

\begin{abstract}
In this paper, changes in the textural properties of butternut squash caused by thermal treatment in a convection steam oven with different levels of temperature, steam, and different process durations were considered. Textural properties of pumpkin pulp were measured in terms of five features (characteristics): hardness, chewiness, gumminess, springiness, and cohesiveness. Pearson's correlation coefficients for measurements of the characteristics indicated significant linear relationships at a significance level of 0.05 . This fact justified the use of multivariate statistical methods to explore the simultaneous impact of temperature, steam, and time on textural attributes of butternut squash. Shapiro-Wilk tests did not disprove the normality of four textural characteristics; namely, hardness, springiness, gumminess and chewiness. Based on the measurements of the four above normally distributed features, three-way multivariate analysis of variance with all double interactions between the factors proved their significant impact on textural properties of butternut squash pulp at a significance level of 0.05 . Additionally, applied multivariate techniques such as canonical correlation analysis, principal component analysis, factor analysis, clustering analysis, and discriminant analysis explained relationships between the factors and characteristics under consideration.
\end{abstract}

Keywords Texture $\cdot$ Butternut squash $\cdot$ Thermal treatment $\cdot$ Multivariate statistical assessment

\section{Introduction}

Currently, healthy and nutritional products in human food are of tremendous importance. One such product is butternut squash, which is characterized by antioxidant and anticancer properties. Pumpkin fruits contain a high content of carotenoids, vitamins A, C and B, various minerals, and organic acids (see e.g., [1-3]). Additionally, pumpkin is low in calories; therefore, it can be successfully used in slimming diets.

Beata Ślaska-Grzywna

beata.grzywna@up.lublin.pl

1 Department of Applied Mathematics and Computer Science, University of Life Sciences in Lublin, Głęboka 28, 20-612 Lublin, Poland

2 Department of Biological Bases of Food and Feed Technologies, University of Life Sciences in Lublin, Głęboka 28, 20-612 Lublin, Poland

3 Department of Power Engineering and Transportation, University of Life Sciences in Lublin, Głęboka 28, 20-612 Lublin, Poland
The quality of butternut squash is considered in the literature of the subject in different aspects, namely, on production and market (see e.g., [3-6]), sensory, chemical or mechanical properties (e.g., [6-9, 11]).

Prior to consumption, pumpkin fruits are subjected to different types of thermal treatments. During these processes, textural properties are changed (e.g., $[1-3,8])$. The aim of this study was to determine changes in the textural properties of butternut squash caused by thermal treatment in a convection steam oven with different process parameters. Textural properties were measured in terms of five features (characteristics): hardness, chewiness, gumminess, springiness, and cohesiveness.

Separate statistical analysis of each feature are presented in [10]. However, the textural characteristics under consideration are mainly mutually significantly correlated; therefore, a multivariate approach was applied to identify any simultaneous influences of thermal treatment parameters on butternut squash texture. MANOVA analysis and selected multivariate techniques were employed, such as canonical correlation analysis, principal component analysis (PCA), 
factor analysis (FA), clustering analysis, and discriminant analysis. All calculations were performed in SAS 9.3 and SAS Enterprise Guide 5.1.

\section{Materials and methods}

In the experiment, butternut squash (Cucurbita moschata Duch.) originating from Portugal was selected as the research material. Details about the raw material, its properties, and the treatments are presented in [10]. In the experiment, three factors were introduced:

- temperature at the levels of 80 and $100{ }^{\circ} \mathrm{C}$,

- steam at the levels of $0 \%, 20 \%, 40 \%, 60 \%, 80 \%$, and $100 \%$ for the temperature of $80{ }^{\circ} \mathrm{C}$, and $0 \%, 20 \%, 40 \%$, and $60 \%$ for the temperature of $100{ }^{\circ} \mathrm{C}$,

- heating times: $5,10,15,20,25$, and $30 \mathrm{~min}$.

Immediately after the thermal treatment, warm samples were measured with the TPA test using a Zwick/Roell Z0.5 strength-testing device. Measurements in the form of texturegrams of strength and time were conducted in six replications. Based on the measurements, the following texture characteristics were determined: hardness $[\mathrm{N}]-$ the maximum force recorded during the first compression cycle; springiness [-] characterizing the degree of shape recovery (calculated as a quotient of sample deformation values during the second and the first compression cycle); gumminess $[\mathrm{N}]$ - quotient of hardness and cohesiveness, chewiness [N] denoting the force required to chew a bite of the food product before swallowing (quotient of hardness, cohesiveness, and elasticity); cohesiveness [-], characterizing internal binding forces ensuring the entity of the product (calculated as a quotient of the fields under the graph of the second and first compression cycles) in [11]. As the final result, a data set was collected containing 360 independent vectors (individual samples), each of five measurable characteristics (features), respectively. Each of the four texture features, i.e. hardness, springiness, chewiness, and cohesiveness, was analyzed separately in [10].

\section{Results and discussion}

The aim of this section is to analyze, using multivariate statistical techniques, the impact of treatment factors on the texture of butternut squash as measured by five features. First, we studied for any significant impact from the main factors and from interactions between them on butternut squash textural characteristics during the thermal treatment using multivariate analysis of variance (MANOVA). Furthermore, multivariate techniques available in SAS Enterprise Guide
5.1 were used to identify similarities and differences between the samples and the characteristics under consideration.

\section{Multivariate analysis of variance (MANOVA)}

To check for the significant impact of the analyzed factors during the thermal treatment-namely, temperature, steam, and duration of heating - on multivariate textural characteristics of butternut squash, a three-way classification model was used in [12] including the main factors and all double interactions between the main factors. To conduct an appropriate analysis, we considered only the same levels for steam at both temperatures: $0 \%, 20 \%, 40 \%$, and $60 \%$.

Six types of null hypotheses were defined:

$H_{\text {Temp }}^{0} \quad$ No overall temperature effect,

$H_{\text {Steam }}^{0} \quad$ No overall steam effect,

$H_{\text {Time }}^{0} \quad$ No overall time effect,

$H_{\text {Temp } \times \text { Steam }}^{0}$ No overall temperature*steam interaction effect,

$H_{\text {Temp } \times \text { Time }}^{0} \quad$ No overall temperature*time interaction effect,

$H_{\text {Steam } \times \text { Time }}^{0} \quad$ No overall steam*time interaction effect.

Before testing the above hypotheses, an additional hypothesis, i.e. that measurements for each of the features under consideration represented normal distributions, was tested using Shapiro-Wilk statistics. Only for some factors of cohesiveness was normality rejected at a significance level of 0.05 . For that reason, four features (hardness, springiness, gumminess, and chewiness) were considered in further analyses. The calculations were performed in SAS 9.3 using the following code:

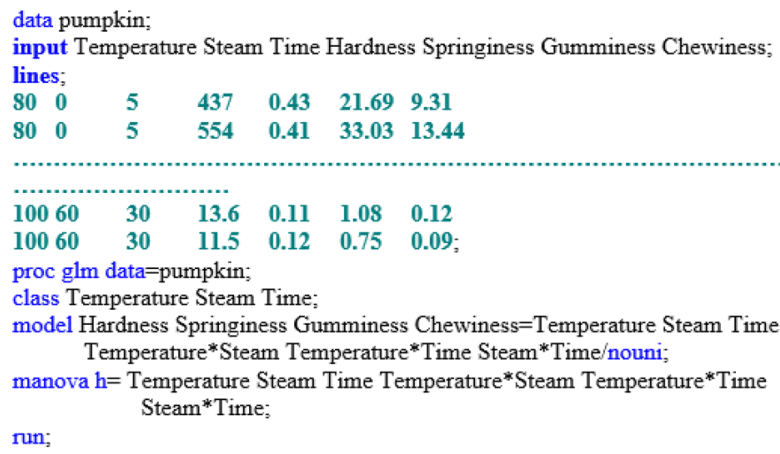

Based on all measurements of the four textural characteristics simultaneously-hardness, springiness, gumminess, and chewiness-all the tests used in MANOVA (Wilks' Lambda, Pillai's Trace, Hotelling-Lawley Trace, and Roy's Greatest Root) rejected all the null hypotheses under consideration. This demonstrated that all factors and their 
interactions had a simultaneous significant impact on the variability of the textural characteristics of butternut squash at a significance level of 0.05 .

\section{Pearson's correlations}

To check the linear relations between the considered features, Pearson's correlation coefficients for each temperature, separately and together for both temperatures, were calculated. The obtained results are presented in Table 1, where the following abbreviations are used: Hard-hardness, Spr-springiness, Gum-gumminess, Chew-chewiness, and Coh-cohesiveness. In Table 1, Pearson's correlations (significant at a 0.05 significance level) are shown in bold.

The correlations between the features under consideration included in Table 1 support the fact that, based on all measurements (last row), most features are significantly correlated. In terms of the temperature of $80^{\circ} \mathrm{C}$ (the second row), only the correlation between springiness and cohesiveness

\section{Canonical correlation analysis}

In this subsection, we concentrate on exploring the relationships between two multivariate sets of variables. The three factors of temperature, steam, and time are considered as the first set of variables, and the textural features under consideration, i.e. hardness, springiness, gumminess, chewiness, and cohesiveness, are the second set of variables. All the regression coefficients between textural characteristics and factors presented in Table 2 are significant at the significance level of 0.05 , except for the regression between cohesiveness and time.

The results in Table 2 show that all the considered factors have a significant negative influence on the texture of butternut squash during thermal treatment, for example, hardness, gumminess and chewiness, and a positive influence on cohesiveness and springiness, with the exception of time.

Based on the canonical analysis, the following first pair of canonical variables:

$\left\{\begin{array}{l}V_{1}=-0.0047 \text { Hard }+1.0463 \mathrm{Spr}-0.0281 \mathrm{Gum}-0.0294 \text { Chew }+24.1402 \mathrm{Coh} \\ W_{1}=0.0819 \text { Temperature }+0.0277 \text { Steam }+0.0185 \text { Time }\end{array}\right.$

is not significant. For the temperature of $100{ }^{\circ} \mathrm{C}$ (the third row), hardness is significantly correlated with gumminess, chewiness, and cohesiveness, and chewiness is also correlated with springiness and gumminess. The most strongly and positively correlated characteristics were hardness and gumminess for temperatures both separately and in total. These facts indicate that, in addition to the statistical analysis of each characteristic separately, additional multivariate analyses should also be performed for all characteristics simultaneously to identify additional sources of variations in the textural attributes of butternut squash. is very highly correlated (0.9134) and explains the total dependence between all canonical variables at a level of more than $90 \%$.

\section{Principal component and factor analyses}

In cases when many features are measured on the same experimental sample, PCA or the more elaborate FA are proposed in the literature to reduce the dimensions of a multivariate data set $[6,7,13-15]$. To apply these methods, we proposed to stabilize the variances of the considered textural

Table 1 Pearson's correlations for textural characteristics with respect to the temperatures $80 \%, 100 \%$ and both (significant coefficients at the level of 0.05 are printed in bold)

\begin{tabular}{|c|c|c|c|c|c|c|c|c|c|c|}
\hline Temperature & Hard-Spr & Hard-Gum & Hard-Chew & Hard-Coh & Spr-Gum & Spr-Chew & Spr-Coh & Gum-Chew & Gum-Coh & Chew-Coh \\
\hline $80{ }^{\circ} \mathrm{C}$ & -0.3431 & 0.8781 & 0.8100 & 0.3615 & -0.1723 & -0.0162 & 0.2808 & 0.9767 & 0.6738 & 0.7157 \\
\hline $100^{\circ} \mathrm{C}$ & 0.0194 & 0.8873 & 0.7535 & -0.2584 & 0.0510 & 0.2714 & -0.0780 & 0.9277 & 0.0325 & 0.0873 \\
\hline Total & -0.1893 & 0.8765 & 0.7765 & -0.1004 & -0.0833 & 0.1052 & 0.0566 & 0.9552 & 0.2058 & 0.2576 \\
\hline
\end{tabular}

Table 2 Regression coefficients between the group of textural features and the group of factors (significant coefficients at the level of 0.05 are given in bold)

\begin{tabular}{lccccc}
\hline Factors & Features & & & \\
\cline { 2 - 5 } & Hardness & Springiness & Gumminess & Chewiness & Cohesiveness \\
\hline Temperature & $\mathbf{- 8 . 3 9 0 6}$ & $\mathbf{0 . 0 0 2 5}$ & $-\mathbf{0 . 2 6 6 0}$ & $\mathbf{- 0 . 0 7 1 3}$ & $\mathbf{0 . 0 0 0 9 8 0}$ \\
Steam & $\mathbf{- 3 . 4 1 8 4}$ & $\mathbf{0 . 0 0 2 7}$ & $-\mathbf{0 . 1 3 5 2}$ & $-\mathbf{0 . 0 3 8 7}$ & $\mathbf{0 . 0 0 0 0 6 8}$ \\
Time & $\mathbf{- 3 . 0 5 0 8}$ & $\mathbf{- 0 . 0 0 6 3}$ & $\mathbf{- 0 . 1 5 0 0}$ & $\mathbf{- 0 . 0 7 4 6}$ & 0.000119 \\
\hline
\end{tabular}


characteristics of butternut squash during thermal treatment; we divided the measurements of hardness by 10 and multiplied the measurements of springiness and cohesiveness by 100. In principal components analysis, new variables are created as linear combinations of the observed characteristics (features) and proper components as principal vectors. Principal component vectors are included in Table 3, and the explanation of variance by the principal components is illustrated in Fig. 1. The most important principal component is the first one and this explains about $52.6 \%$ of the total variability of the original data set. This principal component is strongly correlated with springiness (in bold); moreover, it increases with increasing springiness. The second principal component explained $44.8 \%$ of total data variability and was strongly and also positively correlated with hardness. Summarizing, the first two principal components explained more than $97 \%$ of the variability, so the remaining three principal

Table 3 Principal components of the covariance matrix for texture modified features

\begin{tabular}{lrrrrr}
\hline Features & \multicolumn{1}{c}{ PRIN1 } & PRIN2 & PRIN3 & PRIN4 & \multicolumn{1}{c}{ PRIN5 } \\
\hline 0.1 Hardness & -0.3208 & $\mathbf{0 . 8 5 0 7}$ & -0.3818 & 0.1625 & 0.0355 \\
$\begin{array}{l}\text { 100 Springi- } \\
\text { ness }\end{array}$ & $\mathbf{0 . 9 4 1 3}$ & 0.3339 & -0.0463 & 0.0063 & -0.0218 \\
$\begin{array}{l}\text { Gumminess } \\
\text { Chewiness }\end{array}$ & -0.1046 & 0.3834 & $\mathbf{0 . 7 7 8 6}$ & -0.3013 & -0.3809 \\
$\begin{array}{l}\text { 100 Cohesive- } \\
\text { ness }\end{array}$ & 0.0143 & -0.0041 & 0.3754 & $\mathbf{0 . 9 2 6 4}$ & 0.0263 \\
\hline
\end{tabular}

components explained only about $3 \%$ of data set variability and could be neglected.

Each variable contributes significantly to only one component (printed in bold; see Table 3).

Textural characteristics represented by Pearson's correlations between original features and the first two principal components are illustrated in Fig. 2. We can see that the original textural characteristics, i.e. hardness, gumminess, and chewiness, and their principal component counterparts are close to each other. They are positively correlated with the second principal component and negatively correlated with the first principal component. Another conclusion can be formulated on the basis of springiness or cohesiveness. The correlations for these features are positive both with the first principal component and with the second principal component for springiness. Very small correlations can be observed for cohesiveness with the first two principal component.

Another method for the reduction of the dimensions of data sets is FA in [7]. In a FA, the observed variables are modeled as linear functions of certain unknown factors. The results of FA for the modified data set (after variance stabilization) using the Varimax rotation method are illustrated in Fig. 3.

Hardness, chewiness, and gumminess are very close, i.e. similar (relative to the PCA result). Moreover, cohesiveness and springiness are also closely located. In conclusion, the results of PCA and FA divided the texture characteristics into two separate groups of similar
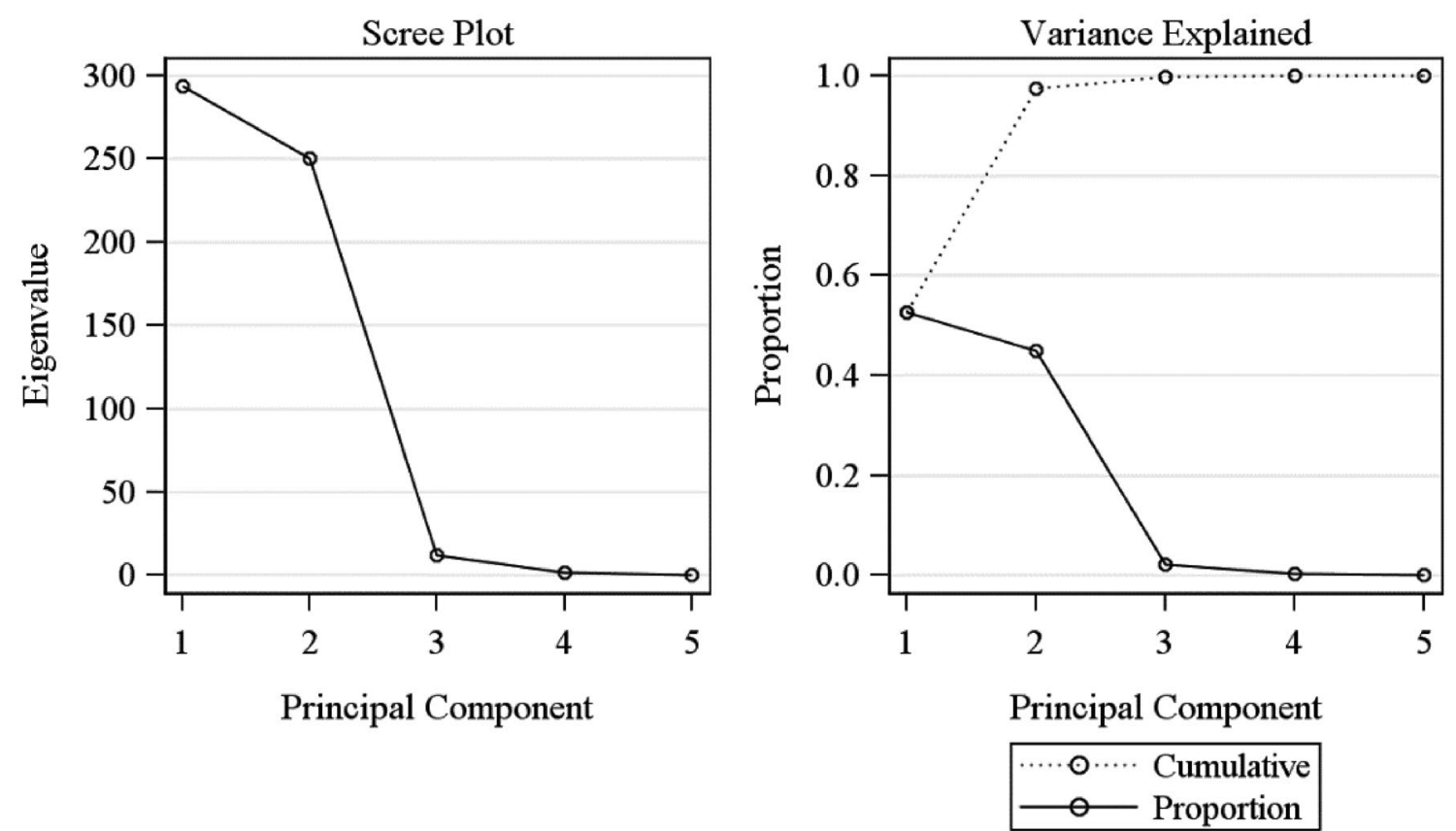

Fig. 1 Eigenvalues of the covariance matrix (left panel) and explanation of variances by the principal component vectors (right panel) 


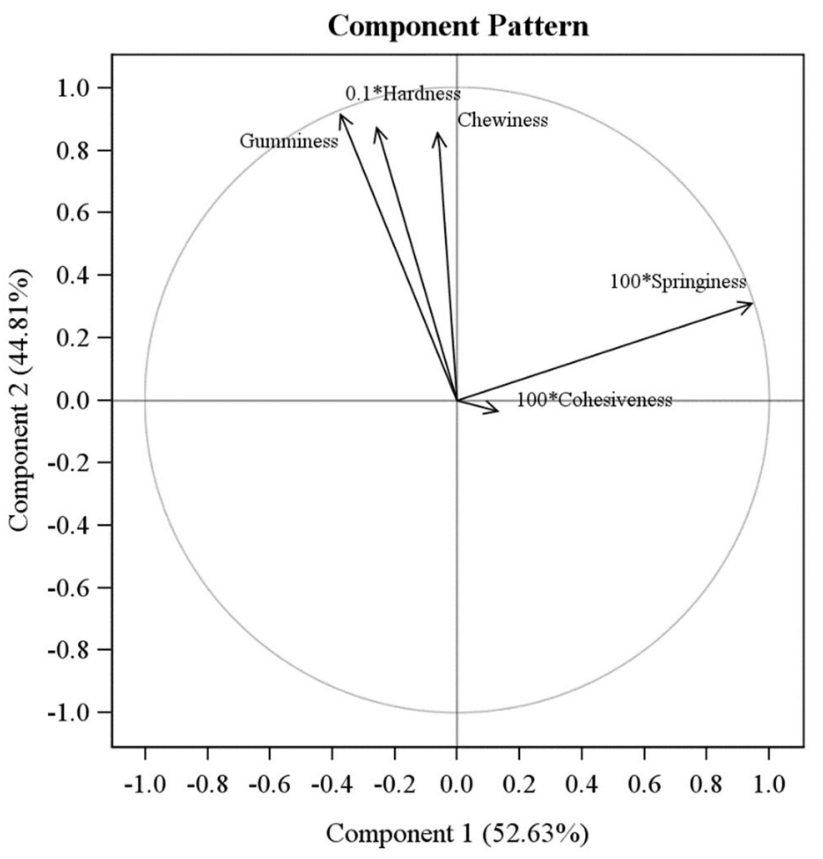

Fig. 2 Textural features in the space of the first two principal components

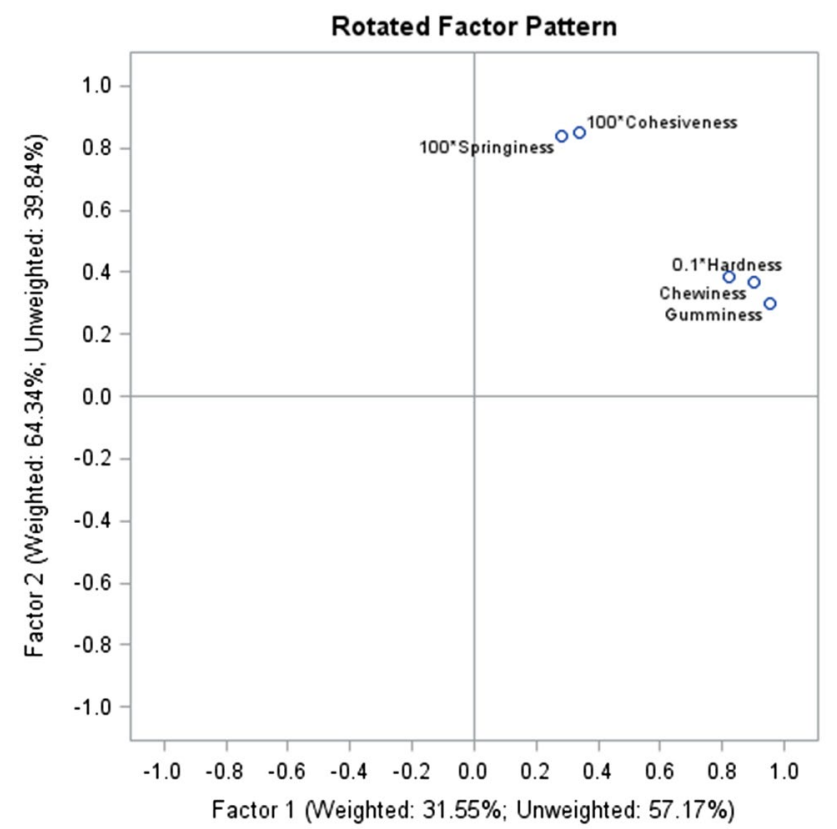

Fig. 3 Textural features in the space of the first two factor components

characteristics. The first group contains hardness, chewiness, and gumminess, and the second comprises cohesiveness and springiness.

\section{Cluster analysis of textural properties}

In this subsection, we concentrate on detection of the similarity between objects (samples) characterized by the same thermal treatment conditions. For comparison, we had a total of $6 \times 6+4 \times 6=60$ different samples, characterizing by averages of all the textural characteristics under consideration. So, for the temperature of $80{ }^{\circ} \mathrm{C}$, we considered six levels of steam and five periods of heating; and for the temperature of $100{ }^{\circ} \mathrm{C}$, we considered four levels of steam and five periods. Cluster analysis was applied to identify the similarity of the variability of the textural characteristics between the samples (e.g., $[13,14])$. The results are presented in Fig. 4.

Figure 4 shows that, in the case where five clusters are considered, those samples for the temperature of $100{ }^{\circ} \mathrm{C}$ or $80{ }^{\circ} \mathrm{C}$ but with higher steam levels are located in the last cluster. Four other clusters mainly contain samples for $80^{\circ} \mathrm{C}$. The first cluster contains samples for the temperature of $80^{\circ} \mathrm{C}$ without steam, and the second cluster contains samples characterized by steam $20 \%$ or without steam for the temperature of $100 \%$. The higher amount of steam divides the samples into the third and fourth clusters.

\section{Discriminant analysis of butternut squash textural properties}

Discriminant analysis was used to answer the question of which of the three factors, i.e. temperature, steam, or duration of thermal treatment, is most responsible for the clear classification of butternut squash textural characteristics in [13]. For each individual factor, based on the original data set for all the features considered, the results are presented in Tables 4, 5 and 6, respectively. When the temperature is regarded as a discriminant variable, the results presented in Table 4 show that the samples at the temperature of $80{ }^{\circ} \mathrm{C}$ are well classified in almost $88 \%$ of cases, while the samples treated at the temperature of $100{ }^{\circ} \mathrm{C}$ are well classified in almost $72 \%$, considering the entire set of measurements of textural characteristics.

To consider steam as a classification variable, the measurements of the steam values $80 \%$ and $100 \%$ for the temperature of $80{ }^{\circ} \mathrm{C}$ were not included in the calculation. The results in Table 5 support the fact that samples with added steam were not best identified. Only samples without steam were recognized the best (in about 67\%), while samples with the steam level of $20 \%$ were recognized the worst (in about $29 \%$ ).

The results when the heating period was considered as a classification variable are presented in Table 6 . 


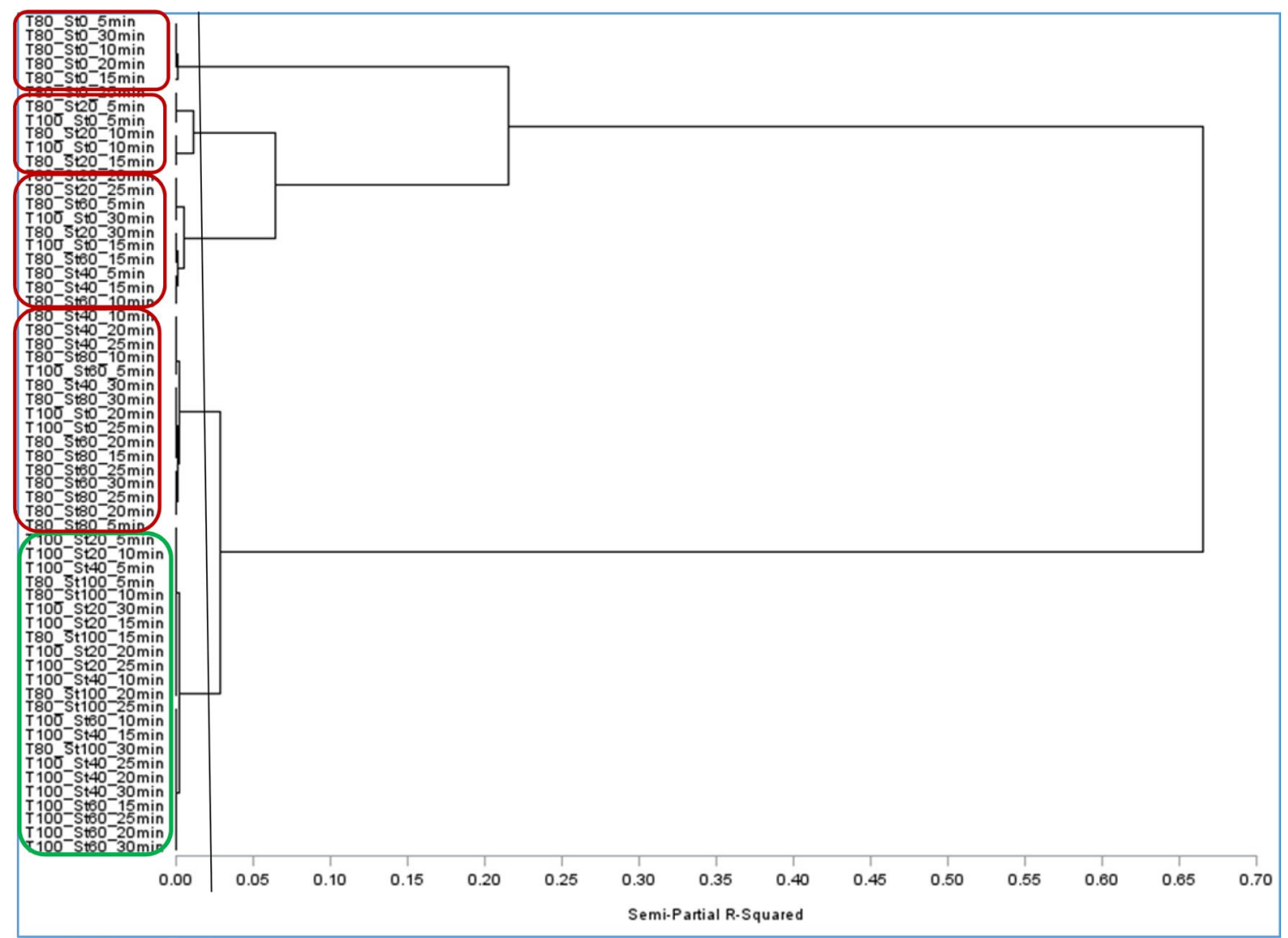

Fig. 4 Clusters for textural characteristics of butternut squash using Ward's minimum-variance method (label T denotes temperature, St—steam and time of heating in minutes)

Table 4 Percentage of well classified data with respect to temperature (in bold)

\begin{tabular}{lll}
\hline Temperature & $80{ }^{\circ} \mathrm{C}$ & $100{ }^{\circ} \mathrm{C}$ \\
\hline $80{ }^{\circ} \mathrm{C}$ & $\mathbf{8 7 . 9 6}$ & 12.04 \\
$100{ }^{\circ} \mathrm{C}$ & 28.47 & $\mathbf{7 1 . 5 3}$ \\
\hline
\end{tabular}

Table 5 Percentage of well classified measurements with respect to steam (in bold)

\begin{tabular}{lrrrr}
\hline Steam & $0 \%$ & $20 \%$ & $40 \%$ & $60 \%$ \\
\hline $0 \%$ & $\mathbf{6 6 . 6 7}$ & 15.28 & 16.67 & 1.39 \\
$20 \%$ & 18.06 & $\mathbf{2 9 . 1 7}$ & 36.11 & 16.67 \\
$40 \%$ & 0.00 & 11.11 & $\mathbf{4 7 . 2 2}$ & 41.67 \\
$60 \%$ & 0.00 & 16.67 & 31.94 & $\mathbf{5 1 . 3 9}$ \\
\hline
\end{tabular}

Based on the results in Table 6, we can say that, in general, the samples were not well recognized with respect to the duration of heating. The best-recognized samples were those for the shortest time of $5 \mathrm{~min}$ (more than 48\%). The other classifications with respect to duration of heating are not satisfactory (below 35\%).

Therefore, we can conclude that the best recognized factor in the thermal treatment of butternut squash was the temperature of heating and the worst factor was the duration of heating.

\section{Conclusions}

The multivariate approach used in the analysis of five textural features of butternut squash during thermal treatment where three factors were applied at several levels allowed the formulation of six general conclusions:

1. The measurements of the textural characteristics (hardness, springiness, gumminess, chewiness, and cohesiveness) confirmed a significant mutual linear dependence according to Pearson's correlations at the significance level of 0.05 . This conclusion was the main motivation to apply multivariate statistical methods in the data set analysis. 
Table 6 Percentage of well classified measurements with respect to time (in bold)

\begin{tabular}{lrlllll}
\hline Time & $5 \mathrm{~min}$ & $10 \mathrm{~min}$ & $15 \mathrm{~min}$ & $20 \mathrm{~min}$ & $25 \mathrm{~min}$ & $30 \mathrm{~min}$ \\
\hline $5 \mathrm{~min}$ & $\mathbf{4 8 . 3 3}$ & 21.67 & 5.00 & 10.00 & 5.00 & 10.00 \\
$10 \mathrm{~min}$ & 16.67 & $\mathbf{2 1 . 6 7}$ & 0.00 & 20.00 & 28.33 & 13.33 \\
$15 \mathrm{~min}$ & 8.33 & 28.33 & $\mathbf{6 . 6 7}$ & 13.33 & 30.00 & 13.33 \\
$20 \mathrm{~min}$ & 5.00 & 26.67 & 6.67 & $\mathbf{2 1 . 6 7}$ & 26.67 & 13.33 \\
$25 \mathrm{~min}$ & 0.00 & 30.00 & 8.33 & 11.67 & $\mathbf{3 5 . 0 0}$ & 15.00 \\
$30 \mathrm{~min}$ & 5.00 & 23.33 & 5.00 & 10.00 & 41.67 & $\mathbf{1 5 . 0 0}$ \\
\hline
\end{tabular}

2. Based on four-dimensional measurements including hardness, springiness, gumminess, and chewiness (without cohesiveness) satisfying the assumption on normality, the three-way MANOVA confirmed that the main factors in thermal treatment (temperature, steam, and the time of heating and all double interactions between them) significantly differentiate the texture of butternut squash pulp at the level of 0.05 .

3. The canonical correlation analysis proved the significant dependence of the textural characteristics with the group of all factors under consideration in the thermal treatment.

4. The PCA and FA with Varimax rotation showed similarities between the variability of hardness, gumminess, and chewiness as well as between springiness and cohesiveness. Moreover, the dimensionality of the textural characteristics can be reduced to two principal components, as they explain $97 \%$ of total measurement variability.

5. Some similarities can be observed using clustering analysis when comparing all samples (pumpkin slices) treated at the temperatures of $80^{\circ} \mathrm{C}$ and $100{ }^{\circ} \mathrm{C}$, with steam added at the levels of $0 \%, 20 \%, 40 \%, 60 \%, 80 \%$ and $100 \%$ for the temperatures of $80{ }^{\circ} \mathrm{C}$, and $0 \%, 20 \%$, $40 \%$, and $60 \%$ for the temperature of $100{ }^{\circ} \mathrm{C}$ and when heated for $5,10,15,20,25$, and $30 \mathrm{~min}$. Nevertheless, it is difficult to specify which of the main factors classifies the samples into the clusters.

6. The discriminant analysis applied to the whole data set of textural characteristics confirmed that the temperature in the treatment classified the samples properly in about $88 \%$ of cases for the temperature of $80^{\circ} \mathrm{C}$ and in about $76 \%$ of cases for the temperature of $100^{\circ} \mathrm{C}$. The duration of heating and the added steam in the thermal treatment were not good discriminators for the samples. These factors frequently classified the samples to neighboring classes.

Open Access This article is distributed acunder the terms of the Creative Commons Attribution 4.0 International License (http://creat ivecommons.org/licenses/by/4.0/), which permits unrestricted use, distribution, and reproduction in any medium, provided you give appropriate credit to the original author(s) and the source, provide a link to the Creative Commons license, and indicate if changes were made.

\section{References}

1. A. Andrejiová, E. Hegedúsová, M. Šlosár, S. Barátová, Acta Univ. Agric. Silvic. Mendel. Brun. 64(2), 387-393 (2016). https://doi. org/10.11118/actun201664020387

2. S.I. Roura, C.E. del Valle, L. Aguero, L.A. Davidovich, J. Food Qual. 30, 538-551 (2007)

3. Q. Zhang, W. Zhou, G. Li, Y. Liu, H. Tang, M. Yu, G. Lu, J. $\mathrm{Su}$, Studies on the compositional properties of main Miben series pumpkin varieties in Southern China. Agric. Sci. Technol. 15(6), 954-963 (2014)

4. R.L. Hultengren, L. Wyatt, M. Mazourek, HortScience 51(11), 1435-1437 (2016). https://doi.org/10.21273/HORTSCI10987-16

5. H.N. Isaboke, P. Mshenga, M. Saidi, Asian J. Agric. Sci. 4(5), 319-324 (2012)

6. V.K. Corrigan, P.L. Hurst, J.F. Potter, N. Z. J. Crop Hortic. Sci. 29, 111-124 (2001)

7. A. Saed-Moucheshi, E. Fasihfar, H. Hasheminasab, A. Rahmani, A. Ahmadi, IJAPP 4(1), 127-141 (2013). http://www.ijappjourn al.com. Accessed Dec 2016

8. C.I. Delgado-Nieblas, J.J. Zazueta-Morales, N. Jacobo-Valenzuela, A. Carrillo-López, E. Aguilar-Palazuelos, I.L. CamachoHernández, A. Quintero-Ramos, J. Food Process. Preserv. (2017). https://doi.org/10.1111/jfpp.12809

9. B. Emadi, V. Kosse, P.K. Yarlagadda, Int. J. Food Prop. 8(2), 277-287 (2011). https://doi.org/10.1080/10942912.2005.10345 418

10. B. Ślaska-Grzywna, A. Blicharz-Kania, A. Sagan, R. Nadulski, Z. Hanusz, D. Andrejko, M. Szmigielski, Ital. J. Food Sci. 28(1), 1-8 (2016). https://doi.org/10.14674/1120-1770/ijfs.v450

11. M. Bourne, Food Texture and Viscosity: Concept and Measurement, 2nd edn. (Elsevier, London, 2002), pp. 182-186, 201-206

12. R. Khattree, N. Naik, Applied Multivariate Statistics with SAS Software, 2nd edn. (SAS Institute Inc., Cary, 2003), pp. 117-137

13. R. Khattree, N. Naik, Multivariate Data Reduction and Discrimination with SAS Software (SAS Institute Inc., Cary, 2000), pp. 25-76, 111-210, 347-442

14. A.L. Tsivelikas, O. Koutita, A. Anastasiadou, G.N. Skaracis, E. Traka-Mavrona, M. Koutsika-Sotiriou, Bras. Arch. Biol. Technol. 52(2), 271-283 (2009)

15. A.C. Atkinson, M. Riani, A. Cerioli, Exploring Multivariate Data with Forward Search (Springer, New York, 2004), pp. 229-278, 367-385 